\title{
Corrosion Inhibition of Copper in 3\% NaCl Solution by Derivative of Aminotriazole
}

\author{
Karima Rhattas ${ }^{1}$, Mohammed Benmessaoud ${ }^{1,2}$, Mostafa Doubi ${ }^{1}$, Najjat Hajjaji ${ }^{1}$, Abdellah Srhiri ${ }^{1}$ \\ ${ }^{1}$ Laboratory of Electrochemistry, Materials and Environment (LEME), Faculty of Sciences, Ibn Tofail University, Morocco; ${ }^{2}$ University \\ of Mohammed V Agdal, Energy Systems Laboratory, Materials and Environment, High School of Technology, Salé Medina, Morocco \\ E-mail: benmessaoud_mma@yahoo.fr
}

Received November $6^{\text {th }}, 2010$; revised January $26^{\text {th }}, 2011$; accepted February $21^{\text {st }}, 2011$.

\begin{abstract}
The inhibiting effect of $\mathrm{N}$-decyl-3-amino-1,2,4-triazole $\left(T N_{10}\right)$ against Copper corrosion in aerated $3 \% \mathrm{NaCl}$, has been developed. Potentiodynamic measurements and electrochemical impedance spectroscopy have been applied to determine the corrosion rate. Scanning electron microscopy (SEM) studied surface morphology has been also used to characterize electrode surface. The obtained results indicate that $T N_{10}$ acts as a good mixed-type inhibitor retarding both anodic and cathodic reactions. An increase of $T_{10}$ concentration leads to a decrease of corrosion rate and inhibition efficiency increase.
\end{abstract}

Keywords: Copper, Triazole, 3\% NaCl Solution, Corrosion, Inhibition

\section{Introduction}

Due to its high electrical and thermal conductivity and good mechanical workability, copper is a material widely used in pipelines for domestic and industrial water utilities, including sea water, heat conductors, and heat exchangers [1]. In spite of the relatively noble potential of copper, its corrosion takes place at a significant rate in sea water and chloride environments [2-9]. It is generally accepted that the anodic dissolution of copper in chloride environments is influenced by the chloride ions concentration. At chloride concentrations lower than $1 \mathrm{M}$, the dissolution of copper occurs through the formation of $\mathrm{CuCl}$, which is not protective enough and is converted to the soluble $\mathrm{CuCl}_{2}$ by reacting with excess chloride [10].

Heterocyclic compounds, especially nitrogen-based ones, are effective inhibitors, being coordinate with $\mathrm{Cu}(0), \mathrm{Cu}(\mathrm{I})$ or $\mathrm{Cu}(\mathrm{II})$ via their nitrogen atoms through lone pair electrons to form polymeric complexes with copper [11-17]. These form an adsorbed protective film on the copper surface, providing inhibition of corrosion by acting as a barrier to aggressive ions such as chloride [18-20]. Polar functional groups such as nitrogen, sulfur, and oxygen and conjugated double bonds are considered reaction centers in establishing the adsorption process $[21,22]$. In others previous work, the influence of organic compounds on the corrosion of copper in neutral solution have been studied [23-28].
The present investigations discusses the results obtained in studying the corrosion behavior of pure copper in aerated $3 \% \mathrm{NaCl}$ solution in absence and in presence of an aminotriazole derivative like N-decyl-3-amino-1, 2,4-triazole noted $\left(\mathrm{TN}_{10}\right)$. The electrochemical methods and surface characterization have been used to characterize the inhibiting effect.

\section{Experimental Conditions}

A classic electrochemical cell with three-electrode configuration was used in this study: a platinum grid as a counter electrode, a rotating disk of pure copper $(99.9 \%)$ as working electrode, and $\mathrm{Ag} / \mathrm{AgCl}$ in $3 \mathrm{M} \mathrm{KCl}$ (SSE) as a reference one.

The working electrode was made of cylinder rod of pure copper (Goodfellow) of $12.5 \mathrm{~mm}$ in diameter. A cylinder rod of about $1 \mathrm{~cm}$ height was fixed to a stainless-steel shaft, and then the lateral part was covered with a cataphoretic epoxyamine base paint (PPG; WT724 + P962). First, the paint was deposited at a constant voltage of $180 \mathrm{~V}$ during $4 \mathrm{~min}$, and then cured at $180^{\circ} \mathrm{C}$ for 30 min. After that, the electrode was embedded into an epoxy resin (Buhler; Epoxycure), and worked out to the cylinder shape, the outer diameter was $21 \mathrm{~mm}$. Only the cross-section of the alloy rod embedded in the epoxy resin was used to form a rotating disk electrode. The cataphoretic coating allowed avoiding any infiltration of electrolyte between the metal and epoxy resin interface. 
Just before each experiment, the electrode surface was polished by emery-paper up to 1000 grit. The corrosive solution was prepared with distilled water and reagent grade chemicals of $\mathrm{NaCl}$. We obtain $3 \%$ of $\mathrm{NaCl}$ solution.

The potentiodynamic measurements were performed using a PGP201 potentiostat/galvanostat. The electrode was immersed for $1 \mathrm{~h}$ in the test solution in free corrosion conditions. Then, the polarization curves were recorded by changing stepwise $(60 \mathrm{mV} / \mathrm{min})$ the potential.

Impedance (EIS) measurements were done using an EG\&G apparatus (model 6310), with a frequency interval ranging from $100 \mathrm{kHz}$ to $10 \mathrm{mHz}$.

The surface morphology of the electrode was performed by using scanning electron microscope (SEM) .

\section{Results and Discussion}

\subsection{Voltammetry Experiments}

The cathodic and anodic polarization curves of the copper obtained with a RDE at $1000 \mathrm{rpm}$ in $3 \% \mathrm{NaCl}$ solution with various $\mathrm{TN}_{10}$ concentrations are presented in Figures 1 and 2, respectively. The range of $\mathrm{TN}_{10}$ concentrations investigated in this work between $10^{-4} \mathrm{M}$ and $10^{-3} \mathrm{M}$. All of these curves were obtained after $1 \mathrm{~h} \mathrm{im}-$ mersion of the electrode in the electrolytic solution at open-circuit corrosion potential ( $\left.E_{\text {corr }}\right)$. Then cathodic and anodic polarization curves were recorded from independent experiments. The initial potential was stated at a slightly more positive potential from $E_{\text {corr }}$ for the cathodic scans, and conversely, it was set at a slightly more negative value from $E_{\text {corr }}$ for the anodic scans.

In absence of $\mathrm{TN}_{10}$, the cathodic current (Figure 1) follows the Tafel law for $E>-0.6 \mathrm{~V} / \mathrm{SCE}$, and then the corrosion current density can be determined readily after diffusion correction $\left(i_{\text {cor }} \approx 127 \mu \mathrm{A} / \mathrm{cm}^{2}\right)$. For potential more negative than $-0.6 \mathrm{~V} / \mathrm{SCE}$, the current plateau observed is ascribed to the limiting current of the dissolved oxygen reduction. The adding of $0.05 \mathrm{mM}$ or $0.1 \mathrm{mM}$ of $\mathrm{TN}_{10}$ into the corrosive medium is accompanied by both a shift of $E_{\text {corr }}$ toward more positive potential, and a decrease of $i_{\text {cor }}$.

It is important to point out that for potential more positive than $-0.4 \mathrm{~V} / \mathrm{SCE}$, the Tafel slope is independent of the inhibitor concentration. In contrast, the cathodic curves in the most negative potential domain (Figure 1) are different in presence and absence of $\mathrm{TN}_{10}$, namely, the limiting diffusion current corresponding to the oxygen reduction is always observed. This may be explained, for instance, by the formation of surface film which hinders the diffusion of dissolved oxygen towards the electrode surface in addition to the hydrodynamic diffusion layer.

The extrapolation of cathodic polarization curve to the

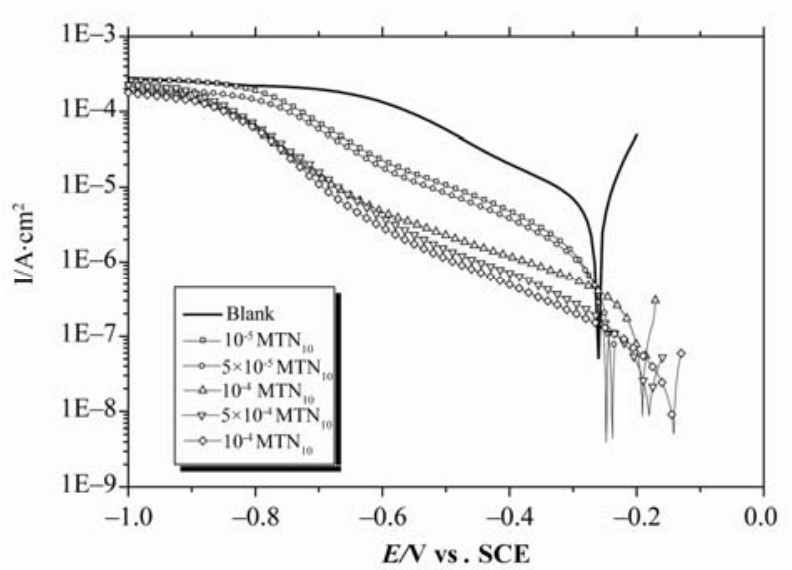

Figure 1. Cathodic polarization curves of copper in aerated $3 \% \mathrm{NaCl}$ without and with various concentrations of inhibitor $\mathrm{TN}_{10}$ at $25^{\circ} \mathrm{C}: \Omega=1000 \mathrm{rpm} ;|\mathrm{dE} / \mathrm{dt}|=60 \mathrm{mVs}^{-1}$.

open-circuit corrosion potential $E_{\text {corr }}$ allowed evaluating the corrosion current density. The results are summarized in Table 1. The inhibiting efficiency $E$ in percent was calculated according to the following expression:

$$
E=100 \frac{i_{\text {corr }}^{0}-i_{0}}{i_{\text {corr }}^{0}}
$$

where $i_{\text {corr }}^{0}$ and $i_{\text {corr }}$ denote the corrosion currents densities in absence and in presence of inhibitor, respectively.

The inhibiting efficiency increases with the $\mathrm{TN}_{10}$ concentration for a given temperature and immersion time, and it reaches $99.2 \%$ for the addition of $1 \mathrm{mM}$ of $\mathrm{TN}_{10}$.

In absence of inhibitor, the anodic curve (Figure 2) exhibits two distinct domains: the first zone is located in the vicinity of the corrosion potential and is characterized by a steep Tafel slope whereas the second zone located towards more positive potentials is characterized by a quite constant current density. This limiting current density is likely governed by the solubility of $\mathrm{CuCl}_{2}$ salt layer as mentioned elsewhere [29].

The anodic polarization curves change dramatically by

Table 1. Corrosion inhibition parameters of cooper in aerated $3 \% \mathrm{NaCl}$ solution without and with addition of $\mathrm{TN}_{10}$ at various concentrations at $25^{\circ} \mathrm{C}$.

\begin{tabular}{ccccc}
\hline $\mathrm{C}, \mathrm{TN}_{10}(\mathrm{M})$ & $b_{\mathrm{c}}(\mathrm{mV} / \mathrm{dec})$ & $E_{\text {corr }}(\mathrm{mV})$ & $I_{\text {corr }}\left(\mu \mathrm{A} / \mathrm{cm}^{2}\right)$ & $E(\%)$ \\
\hline 0 & -239 & -260 & 5.7 & - \\
$10^{-5}$ & -262 & -248 & 1.26 & 77.9 \\
$5 \times 10^{-5}$ & -260 & -238 & 1 & 82.5 \\
$10^{-4}$ & -323 & -191 & 0.27 & 95.3 \\
$5 \times 10^{-4}$ & -234 & -180 & 0.087 & 98.5 \\
$10^{-3}$ & -247 & -142 & 0.047 & 99.2 \\
\hline
\end{tabular}




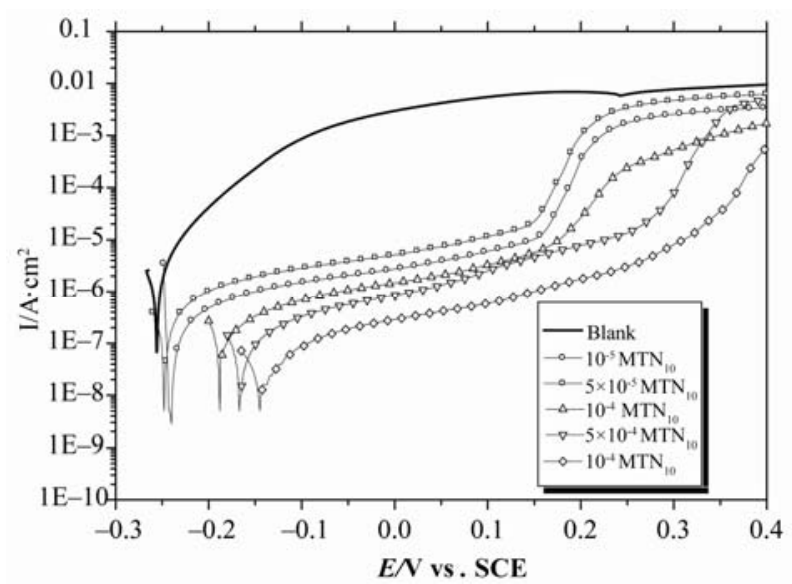

Figure 2. Anodic polarization curves of copper in aerated $3 \% \mathrm{NaCl}$ without and with various concentrations of inhibitor TN10 at $25^{\circ} \mathrm{C}: \Omega=1000 \mathrm{rpm} ;|\mathrm{dE} / \mathrm{dt}|=60 \mathrm{mV} / \mathrm{s}$.

addition of $\mathrm{TN}_{10}$. This change is accompanied by a significant decrease of the anodic current density which is more marked near $E_{\text {corr }}$, and an apparition of large passive domain. This later is clearly observed for various concentrations of $\mathrm{TN}_{10}$. For instance, at $-0.1 \mathrm{~V} / \mathrm{SCE}$ and $-0.15 \mathrm{~V} / \mathrm{SCE}$, the inhibitory efficiency $\mathrm{E}(\%)$ is respectively about $99.7 \%, 99.92 \%$ and about $99.99 \%$ for 0.01 $\mathrm{mM}, 0.1 \mathrm{mM}$ and $1 \mathrm{mM}$ of $\mathrm{TN}_{10}$ respectively. These effects can be explained by the fact that the product tested acts by adsorption on the surface of the material and contributes to an establishment of an inhibiting film relatively compact.

But at higher electrode polarization, the presence of $\mathrm{TN}_{10}$ seems to have low effect, because the anodic current density values are sensibly equal to those obtained without inhibitor. This may be attributed to inhibitor film desorption [30,31] or its destruction under anodic reactions like sample and water oxidations coming under the inhibitor film and in surface sites identified.

Figure 3 shows the curve $\theta=E_{\text {Icorr }} \% / 100$, as a function of $\log$ concentration $C$ of $\mathrm{TN}_{10}$ where $\theta$ is the surface coverage. The $\mathrm{TN}_{10}$ adsorbs on the copper surface according to the Frumkin isotherm model, which is given by the general equation:

$$
\frac{\theta}{1-\theta} e^{-f \theta}=\frac{C}{55.5} e^{\frac{-\Delta G_{\text {ads }}}{R T}}
$$

where $\Delta G_{\text {ads }}$, the free energy of adsorption, is equal to $37.42 \mathrm{~kJ} / \mathrm{mol}$.

The obtained results show that the $\mathrm{TN}_{10}$ inhibit both the cathodic and anodic processes. It acts as a mixed type inhibitor.

\subsection{Electrochemical Impedance Spectroscopy (EIS)}

The impedance diagrams are represented in Nyquist plot,

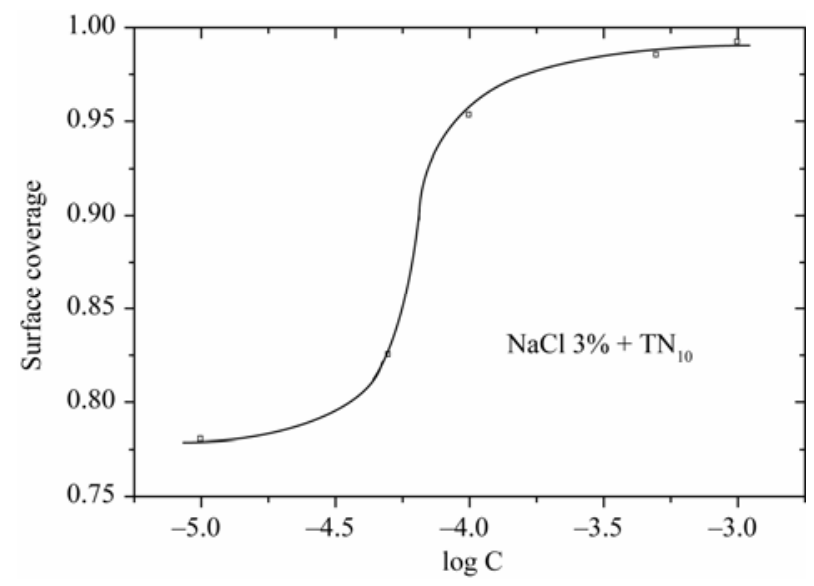

Figure 3. Frumkin isotherm model of $\mathrm{TN}_{10}$ on copper surface.

obtained in solution without and with $10^{-3} \mathrm{M}$ of $\mathrm{TN}_{10}$ inhibitor, are presented in Figure 4. The electrode was immersed in solution at the free corrosion potential until a steady-state was attained.

In the absence of $\mathrm{TN}_{10}$, one capacitive loop is clearly observed with dispersion in low frequencies range. The associated resistance value is about $2620 \mathrm{kOhm} \cdot \mathrm{cm}^{2}$, the corresponding capacity value is in the order of $96 \mu \mathrm{F} / \mathrm{cm}^{2}$. This loop may be attributed to a charge transfer process, occurring on the copper surface. In the same figure we note that the impedance display of the electrode in $\mathrm{TN}_{10}$ containing solution changes in shape and size. On the other hand it can be noticed that the impedance modulus increased dramatically in presence of inhibitor at $10^{-3} \mathrm{M}$ concentration. The presence of two capacitive loops seems to indicate a diffusion contribution to the beginning of the experiment. At high frequency loop, it is found that the resistance value increased in the presence of inhibitor, whereas the double layer capacity value found to be decreased (Table 2). The decrease of capacity value was due to the adsorption of inhibitor

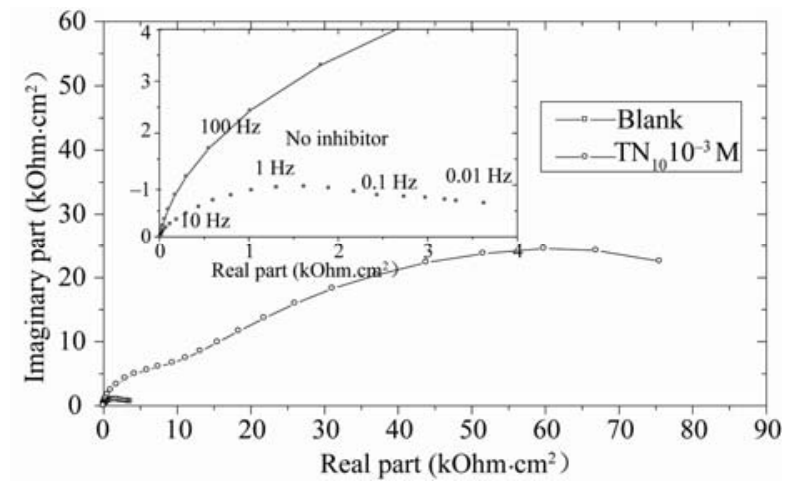

Figure 4. Electrochemical impedance spectra of copper in aerated $\mathrm{NaCl} 3 \%$ without and with $10^{-3} \mathrm{M}$ of $\mathrm{TN}_{10}$ at $25^{\circ} \mathrm{C}$ : $\Omega=1000 \mathrm{rpm}$. 
Table 2. Impedance measurements and inhibition efficiency on copper in $3 \% \mathrm{NaCl}$ solution without and with $10^{-3} \mathrm{M}$ of $\mathbf{T N}_{\mathbf{1 0}}$.

\begin{tabular}{ccccc}
\hline Solutions & $\begin{array}{c}\mathrm{R}_{\mathrm{t}} \\
\left(\mathrm{k} \Omega \cdot \mathrm{cm}^{2}\right)\end{array}$ & $\begin{array}{c}\mathrm{C} \\
\left(\mu \mathrm{F} / \mathrm{cm}^{2}\right)\end{array}$ & $\begin{array}{c}\mathrm{f} \\
(\mathrm{Hz})\end{array}$ & $\begin{array}{c}\mathrm{E} \\
(\%)\end{array}$ \\
\hline $3 \% \mathrm{NaCl}$ & 2,620 & 96 & 0.63 & - \\
$3 \% \mathrm{NaCl}+10^{-3} \mathrm{M} \mathrm{TN}_{10}$ & 43,750 & 7,3 & 4 & 94 \\
\hline
\end{tabular}

molecules on the metal surface acting as barrier to the oxygen diffusion process.

Figure 5 presents the impedance spectra in presence of $10^{-3} \mathrm{M}$ of $\mathrm{TN}_{10}$, when the electrode rotation speed is limited to $500 \mathrm{rpm}$ and $1000 \mathrm{rpm}$ after $1 \mathrm{~h}$ of immersion time. No marked effect of rotation speed on impedance diagrams is noted. This confirms the appearance of a linear broad field in the cathodic domain, when inhibitor is added, and makes it possible to attribute the first loop to a charge transfer process.

\subsection{Film Formed upon Copper Surface}

Figure 6(a) presents the sample surface morphology after $24 \mathrm{~h}$ of immersion time in $3 \% \mathrm{NaCl}$ in absence of $\mathrm{TN}_{10}$ (reference solution). It can be seen that the copper surface is covered by spongy corrosion products. In contrast, in presence of $\mathrm{TN}_{10}$, Figure 6(b) reveals almost no corrosion products are formed, and the grooves due to the initial surface abrasion remain clearly visible after 24 $\mathrm{h}$ immersion. Some precipitates observed are $\mathrm{NaCl}$ crystals that appeared because of insufficient surface rinsing to avoid a wash-out of the corrosion products, if they are present at the surface. The comparison of these two figures reveals a marked inhibiting efficiency of $\mathrm{TN}_{10}$.

Figures 7(a) and 7(b) presents the results of EDX analysis; the copper, chloride, and oxygen are detected

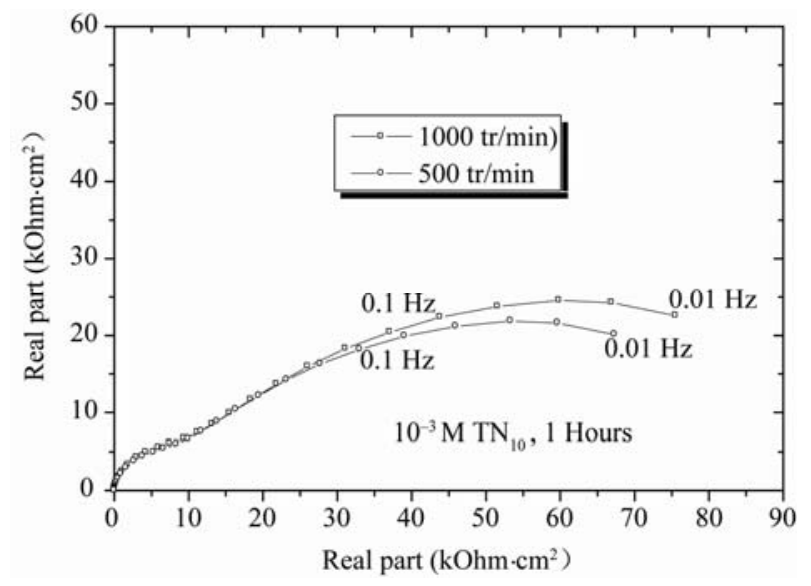

Figure 5. Impedance diagrams of copper in the corrosion test solution in presence of $\mathrm{TN}_{10}$ after $1 \mathrm{~h}$ of immersion at different rotation speed.

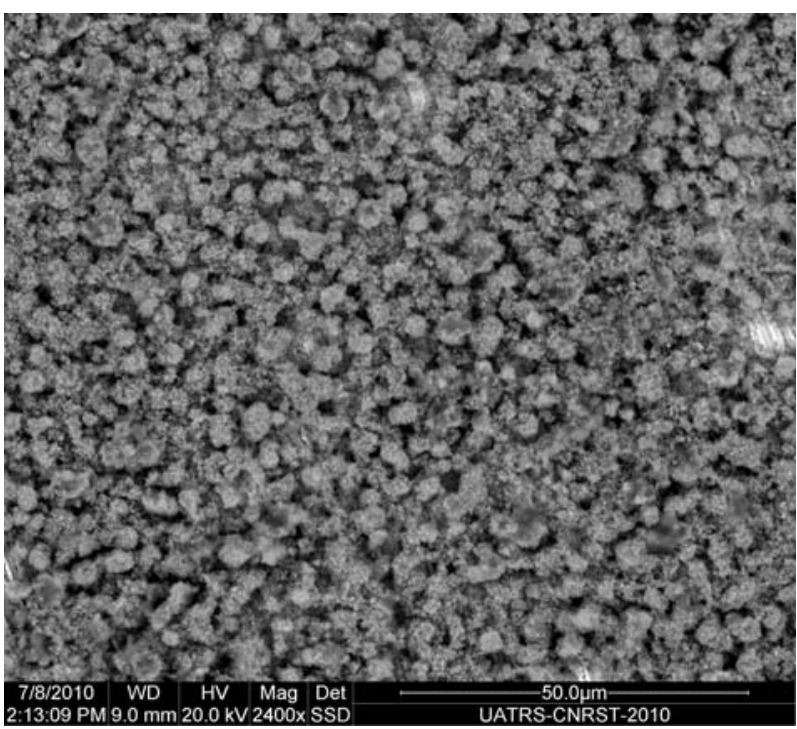

(a)

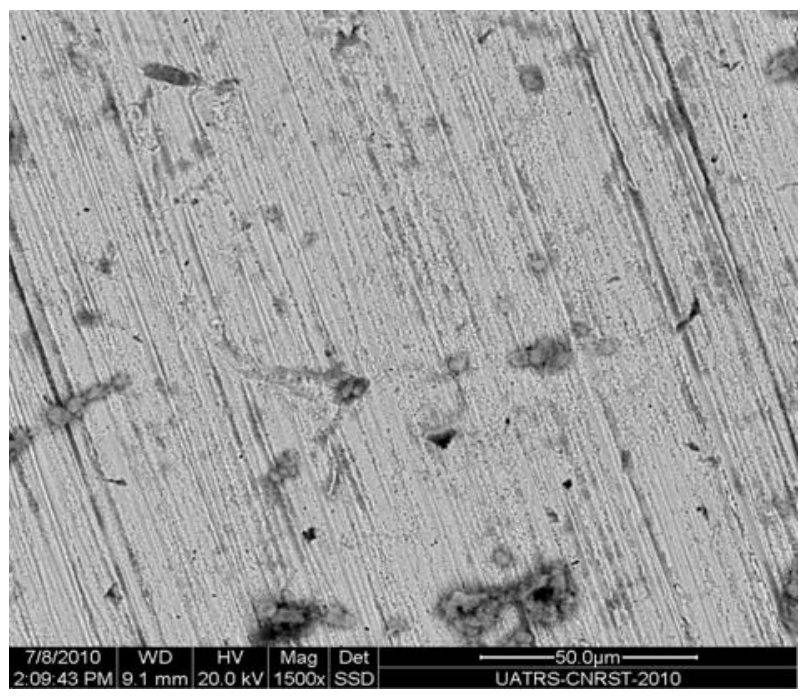

(b)

Figure 6. SEM observation after $24 \mathrm{~h}$ corrosion test at the open circuit, in absence (a) and presence (b) of inhibitor.

after the immersion in the reference solution during $24 \mathrm{~h}$. If the electrode is dipped in the solution containing $1 \mathrm{mM}$ $\mathrm{TN}_{10}$, the peak due to the oxygen decreased dramatically. There is much less corrosion product at the electrode surface. In contrast carbon atoms appear in the inhibiting test, which suggests the adsorption of inhibitor to the electrode surface. The impedance spectra exhibit, as presented above, a time constant allocable to a dielectric surface film. It is very likely that there is a formation of complex layer with $\mathrm{TN}_{10}$ and the corrosion products but its thickness is too thin for SEM observation.

\section{Conclusions}

Electrochemical study showed that TN10 product tested 
C: DATA Clients Universites Univ Med VEST-SAL.E Benmesaoud BAI61 uatrs2010 MEB61

Lable A:MEB6-2

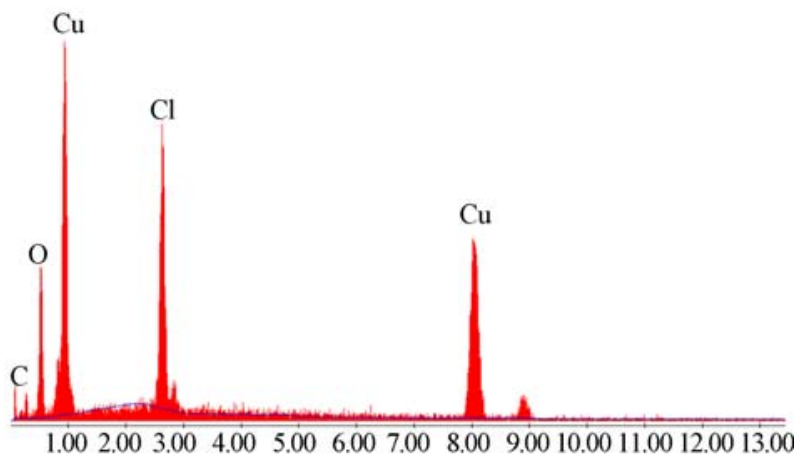

(a)

C: DATA Clients Universites Univ Med VEST-SALE Benmesaoud BA16l uatrs2010 MEB61

\section{Lable A:MEB6-1}

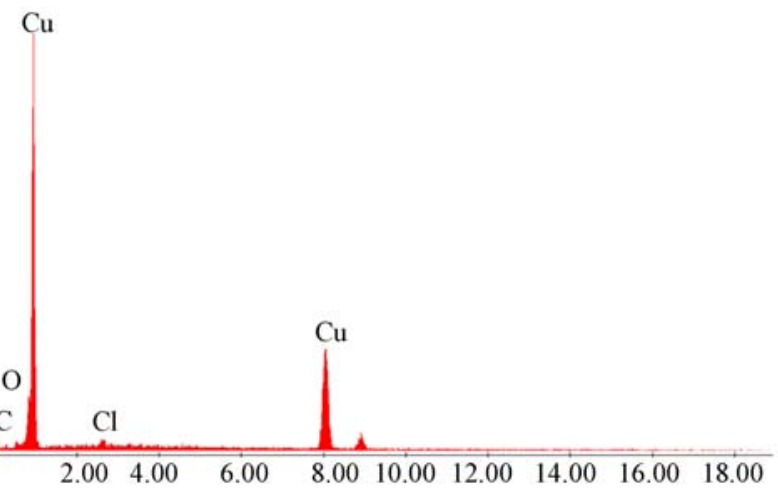

(b)

Figure 7. EDAX spectra obtained at the copper surface after $24 \mathrm{~h}$ corrosion in the corrosion test solution (a) In absence and (b) In presence of $\mathrm{TN}_{10}$.

is a good corrosion inhibitor, against copper corrosion in $3 \% \mathrm{NaCl}$. The inhibitor acts at the same time on the anodic and cathodic electrochemical processes. Polarisation curves showed that the inhibiting effect of this compound results in a clear decrease of the cathodic and anodic current density values especially in the vicinity of corrosion potential. A remarkable inhibiting effect of TN10 was observed when its concentration is higher than 0.05 $\mathrm{mM}$. Its inhibition effect increases with the increase of inhibitor concentration and reaches $98 \%$ at $10^{-3} \mathrm{M}$. These results were confirmed by impedance tests where it was observed that the effect of inhibitor addition is distinguished by an increase of the charge transfer resistance value and a strong reduction of the electrochemical interface capacity value. Surface exam with SEM has shown that inhibitor addition leads to obtain an electrode area without corrosion products as shown in absence of inhibitor. All these lead to propose formation of strong inhibiting film which could passive the metal with very less passivity current densities value.

\section{REFERENCES}

[1] E. M. Sherif, R. M. Erasmus and J. D. Comins, "Corrosion of Copper in Aerated Synthetic Sea Water Solutions and Its Inhibition by 3-Amino-1,2,4-Triazole," Journal of Colloid Interface Science, Vol. 309, No. 2, 2007, pp. 470-477. doi:10.1016/i.jcis.2007.01.003

[2] H. Otmacic, J. Telegdi, K. Papp and E. Stupnisek-Usac, "Protective Properties of an Inhibitor Layer Formed on Copper in Neutral Chloride Solution," Journal of Applied Electrochemistry, Vol. 34, No. 5, 2004, pp. 545-550. doi:10.1023/B:JACH.0000021873.30314.eb

[3] E. M. Sherif and S.-M. Park, "Inhibition of Copper Corrosion in $3.0 \% \mathrm{NaCl}$ Solution by $\mathrm{N}$-Phenyl-1, 4-Phenylenediamine," Journal of the Electrochemical Society, Vol. 152, No. 10, 2005, pp. B428-B433. doi:10.1149/1.2018254

[4] H. O. Curkovic, E. Stupnisek-Lisac and H. Takenouti, "The Influence of $\mathrm{pH}$ Value on the Efficiency of Imidazole Based Corrosion Inhibitors of Copper," Corrosion Science, Vol. 52, No. 2, 2010, pp. 398-405. doi:10.1016/j.corsci.2009.09.026

[5] E. Szocs, G. Vastag., A. Shaban and E. Kalman, "Electrochemical Behviour of an Inhibitor Film Formed on Copper Surface," Corrosion Science, Vol. 38, No. 11, 1996, pp. 2019-2029. doi:10.1016/j.corsci.2006.03.011

[6] E. M. Sherif and S.-M. Park, "2-Amino-5-Ethyl-1,3,4Thiadiazole as a Corrosion Inhibitor for Copper in 3\% $\mathrm{NaCl}$ Solutions," Corrosion Science, Vol. 48, No. 12, 2006, pp. 4065-4079.

[7] M. Finsgar, I. Milosev and B. Pihlar, "Inhibition of Copper Corrosion Studied by Electrochemical and EQCN Techniques," Acta Chimica Slovenica, Vol. 54, 2007 pp. 591-597.

[8] M. A. Amin, "Weight Loss, Polarization, Electrochemical Impedance Spectroscopy," Journal of Applied. Electrochemistry, Vol. 36, No. 2, 2006, pp. 215-226. doi:10.1007/s10800-005-9055-1

[9] K. M. Ismail, "Electrochemical Preparation and Kinetic Study of Poly(o-Tolidine) in Aqueous Medium," Electrochimica Acta, Vol. 52, No. 12, 2007, pp. 3883-3888. doi:10.1016/j.electacta.2006.11.004

[10] El-Warraky, H. A. El-Shayeb and E. M. Sherif, "Pitting Corrosion of Copper in Chloride Solution," Anti-Corrosion Methods and Materials, Vol. 51, No. 1, 2004, pp. 52-61. doi:10.1108/00035590410512735

[11] G. Vastag, E. Szocs, A. Shaban and E. Kalman, "New Inhibitors for Copper Corrosion," Pure and Applied Chemistry, Vol. 73, No. 12, 2001, pp. 1861-1869. doi:10.1351/pac200173121861

[12] E. M. Sherif, "Effects of 2-Amino-5-(Ethylthio)-1,2,4Thiadiazole on Copper Corrosion as a Corrosion in 3\% $\mathrm{NaCl}$ Solutions," Applied Surface Science, Vol. 252, No. 24, 2006, pp. 8615-8623. doi:10.1016/j.apsusc.2005.11.082 
[13] C. T. Wang, S. H. Chen and S. Y. Zhao, "Inhibition Effect of Ac-Treated Mixed Self-Assembled Film of Phenylthiourea and 1-Dodecanethiol on Cooper Corrosion, Journal of the Electrochemical Society, Vol. 151, No. 1, 2004, pp. B11-B15. doi:10.1149/1.1630595

[14] L. Nunèz, E. Reguera, F. Corvo, F. Gonzalez and C. Vazquez, "Corrosion of Copper in Seawater and Its Aerosols in a Tropical Island," Corrosion Science, Vol. 47, No. 2, 2005, pp. 461-484. doi:10.1016/j.corsci.2004.05.015

[15] E. M. Sherif, R. M. Erasmus and J. D. Comins, "Effects of 3-Amino-1,2,4-Triazole on the Inhibition of Copper Corrosion in Acidic Chloride Solutions," Journal of Colloid Interface Science, Vol. 311, No. 1, 2007, pp. 144151. doi:10.1016/j.jcis.2007.02.064

[16] F. Zucchi, G. Trabanelli and C. Monticelli, "The Inhibition of Copper Corrosion in $0.1 \mathrm{M} \mathrm{NaCl}$ under Heat Exchange Conditions," Corrosion Science, Vol. 38, No. 1, 1996, pp. 147-154. doi:10.1016/0010-938X(96)00121-7

[17] V. Lakshminarayanan, K. Kannan and S. R. Rajagopalan, "Cyclic Voltammetric Behavior of Certain Copper-Azole Systems Using Carbon Paste Electrodes," Journal of Electroanalytical Chemistry, Vol. 364, No. 1-2, 1994, pp. 79-86. doi:10.1016/0022-0728(93)02924-7

[18] M. Scendo and M. Hepel, "Inhibiting Properties of Benzimidazole Films for $\mathrm{Cu}(\mathrm{II}) / \mathrm{Cu}(\mathrm{I})$ Reduction in Chloride Media Studied by RDE and EQCN Techniques," Journal of Electroanalytical Chemistry, Vol. 613, No. 1, 2008, pp. 35-50. doi:10.1016/j.jelechem.2007.10.014

[19] E. M. M Sutter, F. Ammeloot, M. J. Pouet, C. Fiaud and R. Couffignal, "Heterocyclic Compounds Used as Corrosion Inhibitors: Correlation between ${ }^{13} \mathrm{C}$ and ${ }^{1} \mathrm{H}$ NMR Spectroscopy and Inhibition Efficiency," Corrosion Science, Vol. 41, No. 1, 1999, pp. 105-111. doi:10.1016/S0010-938X(98)00099-7

[20] F. Zucchi, G. Trabanelli and M. Fonsati, "Tetrazole Derivatives as Corrosion Inhibitors for Copper in Chloride Solutions," Corrosion Science, Vol. 38, No. 11, 1996, pp. 2019-2029. doi:10.1016/S0010-938X(96)00094-7

[21] E. M. Sherif and S.-M. Park, "Effect of 2-Amino-5Ethylthio-1,3,4-Thiadiazole on Copper Corrosion Aerated Acidic Pickling Solutions," Electrochimica Acta, Vol. 51, No. 28, 2006, pp. 6556-6562. doi:10.1016/j.electacta.2006.04.047

[22] K. F. Khaled, "Guanidine Derivative as a New Corrosion Inhibitor for Copper in 3\% $\mathrm{NaCl}$ Solution," Materials Chemistry and Physics, Vol. 112, No. 1, 2008, pp. 104-111. doi:10.1016/j.matchemphys.2008.05.052
[23] El-Sayed M. Sherif, R. M. Eramus and J. D. Comins "Inhibition of Corrosion Processes on Copper in Aerated Sodium Chloride Solution by 5-(Aminophenyl)-Tetrazole," Journal of Applied Electrochemistry, Vol. 39, No. 1, 2009, pp. 83-91. doi:10.1007/s10800-008-9641-0

[24] El-Sayed M. Sherif, A. M. El Shamy, M. M. Ramla and A. O. H. El Nazhawy, "5-(Phenyl)4H-1,2,4-Triazole-3-Thiol as a Corrosion Inhibitor for Copper in $3.5 \% \mathrm{NaCl}$ Solutions," Materials Chemistry and Physics, Vol. 102, No. 2-3, 2007, pp. 231-239.

[25] M. Yadav and D. Sharma, "Dithiobiruts as Corrosion Inhibitors for Copper in 3.5\% NaCl Solution," Portugaliae Electrochimica Acta, Vol. 28, No. 1, 2010, pp. 51-62. doi: $10.4152 /$ pea.201001051

[26] El-Sayed M. Sherif and A. A. Almajid, "Surface Protection of Copper in Aerated 3.5\% Sodium Chloride Solutions by 3-Amino-5-Mercapto-1,2,4-Triazole as a Copper Corrosion Inhibitor," Journal Applied Electrochem, Vol. 40, No. 8, 2010, pp. 1555-1562. doi:10.1007/s10800-010-0140-8

[27] H. O. Curkovic, E. Stupnisek-Lisac and H. Takenouti "Electrochemical Quartz Crystal Microbalance and Electrochemical Impedance Spectroscopy Study of Copper Corrosion Inhibition by Imidazoles," Corrosion Science, Vol. 51, No. 10, October 2009, pp. 2342-2348. doi:10.1016/j.corsci.2009.06.018

[28] E. D’Elia, O. E. Barcia, O. R. Mattos, N. Pébère and B. Tribollet, "High-Rate Copper Dissolution in Hydrochloric Acid Solution," Journal of the Electrochemical Society, Vol. 143, No. 3, 1996, pp. 961-967. doi:10.1149/1.1836565

[29] Z. A. Chikh, "Contribution à L'étude de L'inhibition de la Corrosion d'un Alliage $\mathrm{Cu}-\mathrm{Zn}$ en Milieu $\mathrm{NaCl}$ 3\% par Couplage de Méthodes Électrochimiques et Spectroscopiques," Doctoral Dissertation, Ibn Tofail University, Kenitra, 2001.

[30] Z. A. Chikh, B. Assouli, A. B. Bachir, N. Hajjaji, A. Frignani, F. Zucchi and A. Srhiri, "A New Corrosion Inhibitor for $\mathrm{Cu} 60-\mathrm{Zn}$ Brass in 3\% $\mathrm{NaCl}$ Solution," Proceedings of the $9^{\text {th }}$ European Symposium on Corrosion Inhibitors, Ferrara, Vol. 2, 2000, pp. 687-698.

[31] A. Srhiri, B. Trachli, N. Hajjaji, M. Keddam, H. Takenouti, A. Frignani and F. Zucchi, "Corrosion Inhibition of Copper in Chloride Solution by Triazole Derivatives," Proceedings of the $9^{\text {th }}$ European Symposium on Corrosion Inhibitors, Ferrara, Vol. 2, 2000, pp. 627-637. 